Supplement of Hydrol. Earth Syst. Sci., 23, 73-91, 2019

https://doi.org/10.5194/hess-23-73-2019-supplement

(c) Author(s) 2019. This work is distributed under

the Creative Commons Attribution 4.0 License.

(c) (1)

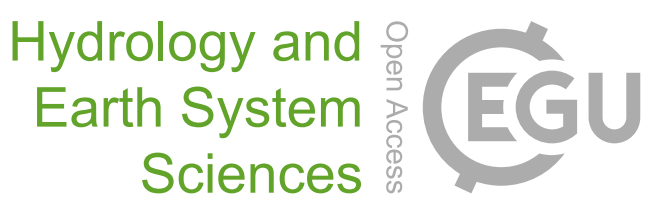

Supplement of

\title{
A large sample analysis of European rivers on seasonal river flow correlation and its physical drivers
}

Theano Iliopoulou et al.

Correspondence to: Theano Iliopoulou (anyily@central.ntua.gr)

The copyright of individual parts of the supplement might differ from the CC BY 4.0 License. 


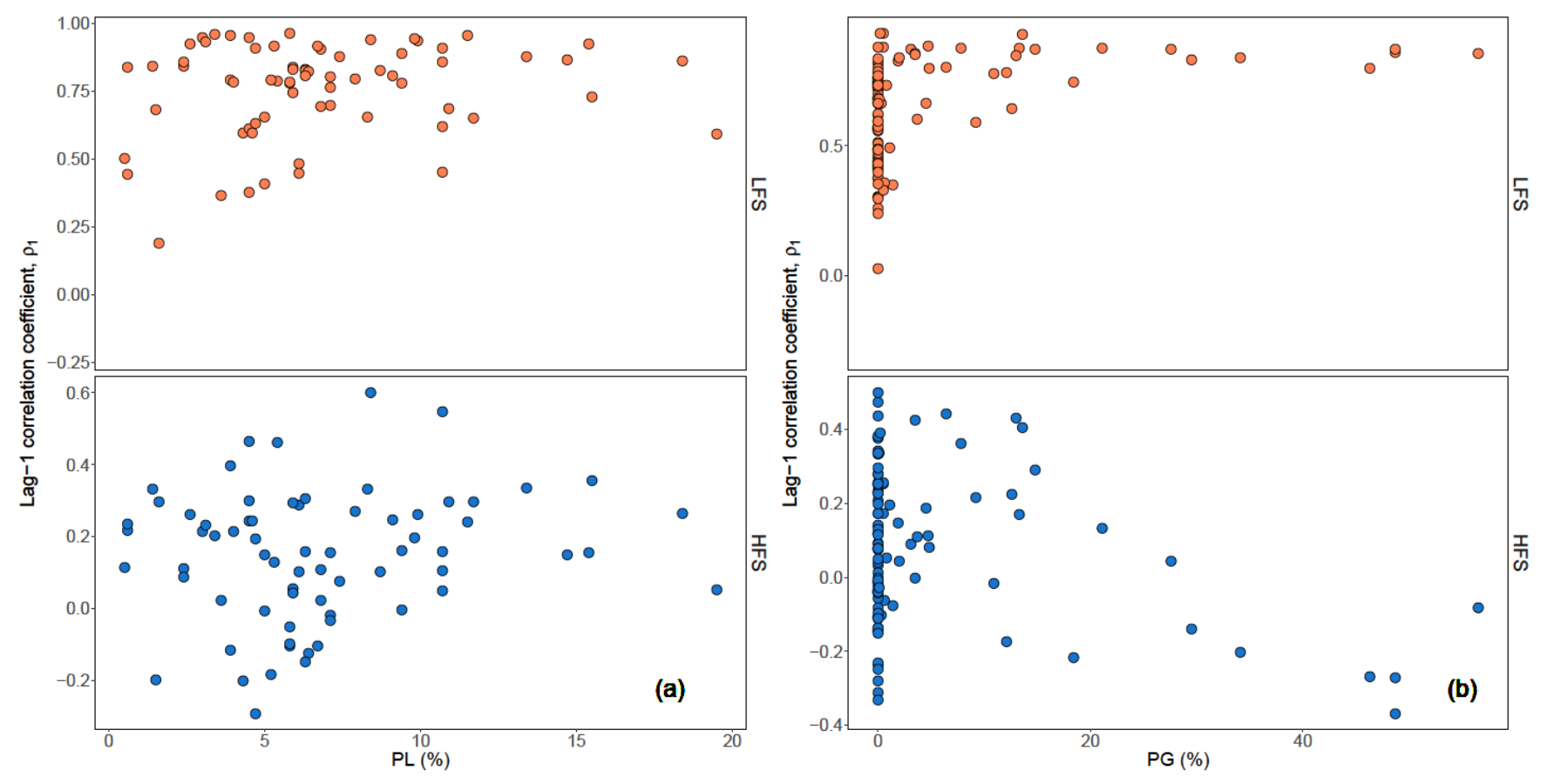

Figure S1. Scatterplots of lag-1 HFS (bottom) and LFS (top) streamflow correlations versus percentage of lakes PL of the Swedish catchments (a) and percentage of glaciers PG of the Austrian catchments (b).

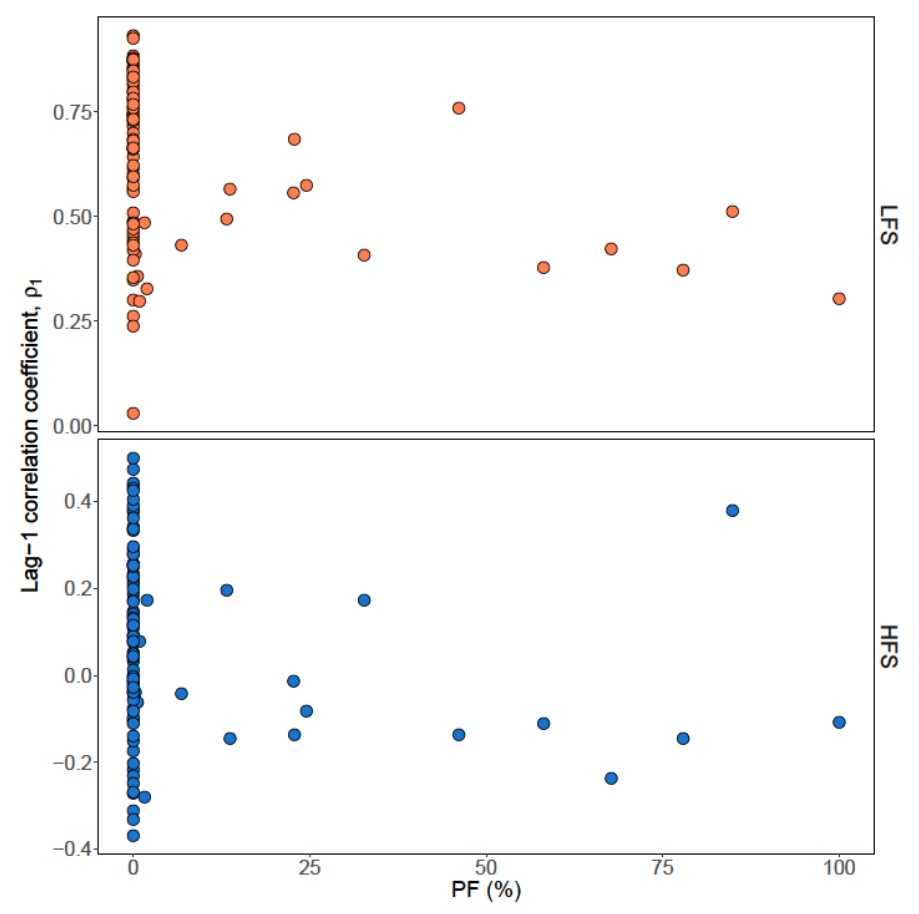

Figure S2. Scatterplots of lag-1 correlation vs percentage of flysch area coverage PF for HFS (bottom) and LFS (top) analysis for the Austrian catchments. 